Original Research

\title{
Effect of Foot Exercise and Care on Peripheral Vascular Status in Patients with Diabetes Mellitus
}

\section{Selpina Embuai ${ }^{1}$, Hani Tuasikal ${ }^{2}$ and Moomina Siauta ${ }^{1}$}

${ }^{1}$ Universitas Kristen Indonesia Maluku, Indonesia

${ }^{2}$ Akper Rumkit Tk III Dr. J. A. Latumeten Ambon, Indonesia

\section{ABSTRACT}

Introduction: Diabetes mellitus is a cause of health problems which occurs in most countries. Approximately $13-15 \%$ of all patients with diabetes mellitus will experience peripheral circulatory disorders. Foot exercise and foot care are interventions that can be implemented to prevent foot ulcers.

Methods: This study employed a pre-post-test quasi-experimental design with a control group. The sample consisted of 94 patients with diabetes mellitus who were assigned to the intervention group $(n=47)$ and the control group $(n=47)$ respectively. Consecutive sampling was used to recruit the samples. The instruments used to collect the data included 10 g monofilament for the diabetic neuropathy test, a HbA1c test and a sphygmomanometer. The collected data was analyzed using a paired t-test.

Results: The results of this study showed there to be significant effects from foot exercise and foot care on the HbA1c test, in relation to the frequency of the dorsalis pedis artery and diabetic neuropathy with a significance value of $0.00(\mathrm{p}<0.05)$. However, in the ankle-brachial index measurement, there were no significant differences between the intervention and control groups with a significance value of $0.26(p>0.05)$.

Conclusion: Foot exercise and foot care can be one of the independent nursing interventions used to prevent the complications of diabetes mellitus, as they have been proven to improve the peripheral vascular status of patients with diabetes mellitus by $70-80 \%$.
\end{abstract}

\section{ARTICLE HISTORY}

Received: Dec 26, 2019

Accepted: Dec 31, 2019

\section{KEYWORDS}

foot exercise; peripheral vascular; diabetes mellitus

\section{CONTACT}

Selpina Embuai

$\bowtie$ selfiembuai@gmail.com

$\fallingdotseq$ Universitas Kristen Indonesia

Maluku, Indonesia

Cite this as: Embuai, S., Tuasikal, H., \& Siauta, M. (2019). Effect of Foot Exercise and Care on Peripheral Vascular Status in Patients with Diabetes Mellitus. Jurnal Ners, 14(3si), 5-13. doi:http://dx.doi.org/10.20473/jn.v14i3(si).16943

\section{INTRODUCTION}

Diabetes mellitus is a serious chronic disease that requires considerable attention. It has become a leading cause of health problems in almost all countries (Fujiwara et al., 2011). About 15\% of patients with diabetes mellitus will experience foot ulcers - a serious complication that may result in the amputation of the lower extremities (Mahfud, 2012); (Kotru, Kotru, \& Joshi, 2015). Seventy percent of foot ulcers can occur within a period of five years (Kotru et al., 2015). Moreover, 85\% of patients undergoing amputations are associated with foot ulcers due to diabetes mellitus (Kotru et al., 2015).

The prevalence of patients with diabetes mellitus is increasing every year. According to the National Diabetes Fact Sheet (2014), the total prevalence of diabetes in America in 2012 was 29.1 million (9.3\%). Of this number, 21 million were diagnosed diabetes and the remaining 8.1 million were undiagnosed with diabetes mellitus. The International Diabetes Federation (IDF) in 2013 reported that the prevalence of diabetes mellitus in Indonesia was approximately 8.5 million people and this number makes Indonesia ranked seventh in the world in terms of diabetes population (IDF, 2013). Furthermore, Perkeni (2015) reported that the number of patients with diabetes mellitus in Indonesia had reached 9.1 million people. As a result, Indonesia has shifted up from number seven to the top five countries with the highest number of diabetics in the world (Ramadhan \& Marissa, 2015). 
Peripheral neuropathy is one of the serious complications of diabetes. Recent data shows that one out of five people with diabetes mellitus (20\%) experience peripheral neuropathy. The risk of peripheral neuropathy is two times higher in people with diabetes mellitus. A combination of peripheral neuropathy is that the problems associated with blood supply to the legs can cause foot ulcers and slow wound healing that leads to amputation. Around $40-70 \%$ of amputations in lower extremities are caused by diabetes mellitus (Studi, Ilmu, Keperawatan, \& Indonesia, 2012).

The long-term vascular complications of diabetes mellitus involve small vessels, microangiopathy, medium vessels, and large vessels leading to the occurrence of macroangiopathy. In particular, macroangiopathy is a diabetes-specific lesion that attacks the retinal capillaries and arterioles (diabetic retinopathy), renal glomerulus (diabetic nephropathy), peripheral nerves (diabetic neuropathy), muscles and skin. In the neural tissue, there is an accumulation of sorbitol and fructose and a decrease in myoinositol which causes neuropathy. Biochemical changes in the neural tissues will disrupt the metabolic activities of the Schwann cells and cause a loss of axon. The speed of motoric conduction will decrease in the early stage of neuropathy, resulting in pain, paresthesias, reduced vibration, propioseptic sensations, and motoric disorders accompanied by a loss of reflex of the internal tendon, muscle weakness, and atrophy. These changes bring in higher risks of lesions which later develop into diabetic ulcers.

To deal with diabetes mellitus, the American Diabetes Association (2016) recommends a collaborative service of multidisciplinary teams involving several fields; one of which is nursing. In general, there are four main objectives related to providing the services which include health promotion, disease prevention, patient care, and the fulfillment of patient needs (Aalaa, Malazy, Sanjari, Peimani, \& Mohajeri-Tehrani, 2012). One of the preventive actions to deal with diabetes mellitus is self-care. Diabetes self-care is an important factor in controlling the disease. Almost $95 \%$ of diabetes care is influenced by the consistency of the clients and their families in monitoring their blood glucose, nutrition, physical activity and treatment.

Nurses as health care providers play an important role in preventing diabetic ulcers and the risk of amputation of the lower extremities through foot care and foot exercises. Nurses should not only facilitate and provide foot care and foot exercises to the patients but they should also provide health education to the family about the importance of having their blood sugar checked and any alternative efforts made to prevent complications due to diabetes mellitus (Aalaa et al., 2012).

Practically, preventive foot care includes washing the feet properly, drying the feet carefully, keeping the area between the toes dry, using lotions as a moisturizer, using shoes and socks as recommended, cutting the nails as recommended, conducting foot inspections every day, and ensuring that the temperature of the water used to clean the feet is below $37^{\circ} \mathrm{C}$. In addition to foot care, diabetes mellitus may be overcome by managing the factors affecting glucose reduction, namely physical activity, insulin level, diet and therapy (Kotru et al., 2015). Physical activities in the form of exercises can function as a treatment for diabetes mellitus. These exercises should be measurable, organized, controlled and regularly practiced. Foot exercises are one of the recommended activities for patients with diabetes mellitus. Diabetic foot exercises can prevent injuries and help blood circulation especially in the lower extremities and legs in patients with diabetes mellitus (Kotru et al., 2015).

A preliminary study conducted at RSUD Dr. M. Haulussy Ambon found there to be an increased number of patients with diabetes mellitus undergoing treatment in the hospital. In 2015, 773 people with diabetes mellitus were found. From January to November 2016, there were 1045 patients with diabetes mellitus undergoing treatment in the hospital; 53 of whom had diabetic ulcers. Some interviews were also conducted with the health workers and patients regarding the nursing interventions given. Of the ten patients interviewed, $100 \%$ reported that they had never had any foot care and that they did not know how to perform it. Moreover, there were no programs of foot care or foot care education implemented in the hospital units.

Studies on foot exercises and care have been conducted by some researchers. Kotru et al. (2015) conducted a study about foot care practices concerning new diabetic foot ulcers in patients with type 2 diabetes mellitus. The results revealed that $34 \%$ of 108 patients had abnormal plantar foot pressure on podiascan, $20 \%$ had foot disorders (calluses, claw toes, redness, etc.), and $17 \%$ had peripheral vascular disease. After one year was observed in the intervention group, new ulcers or diabetic feet were found in only $18 \%$ of patients whereas in the control group, new ulcers or diabetic feet developed in 31\% of patients (Kotru et al., 2015).

Priyanto (2012) conducted a study on the effects of foot exercises on foot sensitivity and blood sugar levels on an aggregate of elderly people with diabetes mellitus in Magelang. The results reported that the elderly people who were given the intervention of foot exercises had better blood sugar levels $(p=0.000)$ and better foot sensitivity $(p=0.000)$ than those receiving no intervention. Therefore, it is important to investigate the effects of foot exercise and care on peripheral vascular status in patients with diabetes mellitus (Studi et al., 2012).

\section{MATERIALS AND METHODS}

This study used a pre-post-test quasiexperimental design with a control group and it was conducted in RSUD Dr. M. Haulussy Ambon from February to May 2017.The sample consisted of 94 
patients with diabetes mellitus undergoing treatment in the hospital and they were assigned to the intervention group $(n=47)$ and the control group $(n=47)$. A consecutive sampling technique was used to recruit the samples. The instruments used to collect the data were $10 \mathrm{-g}$ monofilament of SemmesWeinstein for the diabetic neuropathy test. This test examines the Merkel and Meissner receptor function and the relationship with the diameter of large nerve fibers and the associated guidelines for measuring sensation and pressure. The HbA1c test guidelines for taking blood samples for HbA1c examination, a sphygmomanometer for measuring blood pressure, ankle-brachial index guidelines and the measurement of the dorsalis pedis artery were used to identify peripheral blood circulation, foot care and foot exercise. The data was analyzed using a paired sample t-test. Regarding the use of monofilament, the mean difference test in the intervention group was performed using McNemar. Meanwhile, for the assessment of $\mathrm{HbA} 1 \mathrm{c}, \mathrm{ABI}$, and the frequency of the pulse of the dorsalis pedis artery, the Wilcoxon test was used. The Mann-Whitney test was used to determine the mean comparison of the two groups.

\section{RESULTS}

In this study, a paired t-test was carried out to test the mean difference of the data. Prior to the test, there was an underlying assumption regarding the normality of the data which was tested using ShapiroWilk. If the data did not meet the assumption, then the Wilcoxon test would be used instead. In this test, the measured variables were monofilament, $\mathrm{HbA} 1 \mathrm{c}, \mathrm{ABI}$ and the pulse frequency of the dorsalis pedis artery. See on Table 2 .

The mean difference test for the two groups was performed to determine whether there were significant differences between the control and intervention groups based on the measured variables. Before the test, the normality of data was examined using the Shapiro-Wilk test. If the data was not normally distributed, then the Mann-Whitney test would be used. In this study, the variables were measured using a monofilament, HbA1c, $\mathrm{ABI}$, and the pulse frequency of the dorsalis pedis artery. See on Table 3 .

\section{DISCUSSION}

The test results for the monofilament showed that there were significant differences between the intervention group and the control group. At the time of the initial assessment, this study required that all of the respondents had to have their peripheral neuropathy status tested using a monofilament. When tested, the respondents were unable to sense four out of the ten location points examined, indicating that the patients experienced peripheral neuropathy. The patients were given the intervention of foot exercises and foot care for three months before the evaluation was carried out. The results showed there to be a significant effect in which 41 respondents experienced a positive change or their peripheral neuropathy status was improved. Meanwhile, six respondents still had a neuropathy status but their condition was getting better. This

Table 1. Description of the data in the intervention group and the control group

\begin{tabular}{lccc}
\hline Variable & $\begin{array}{c}\text { Intervention Group } \\
\text { (n= 47) }\end{array}$ & $\begin{array}{c}\text { Control Group } \\
\text { (n= 47) }\end{array}$ & p-value \\
\hline Monofilament* & $0 \%$ & & \\
$\quad$ Negative & $100 \%$ & $0 \%$ & $-* *$ \\
$\quad$ Positive & & $100 \%$ & \\
Vascular Status & $9.3 \pm 2.9$ & $8.2 \pm 2.2$ & 0.14 \\
$\quad$ HbA1c & $0.85 \pm 0.07$ & $0.8 \pm 0.6$ & 0.01 \\
ABI & $58.5 \pm 2.24$ & $58.5 \pm 2.2$ & 1.00 \\
$\quad$ Pulse frequency of the dorsalis pedis artery & & & \\
\hline
\end{tabular}

*Monofilament measurement was performed using the Chi-Square test. The HbA1c. ABI and the frequency of the pulse of the dorsalis pedis artery were tested using the Mann Whitney test and presented as a percentage (\%); **The data results from monofilament measurement were not tested as they were included in the inclusion criteria with equal values in both groups; *** Vascularity: HbA1c. ABI and the frequency of the dorsalis pedis artery pulse were presented in Mean and SD.

Table 2. The summary of the mean difference test between the intervention and control

\begin{tabular}{|c|c|c|c|c|c|c|}
\hline \multirow{2}{*}{ Variabel } & \multicolumn{2}{|c|}{ Intervention } & \multirow[b]{2}{*}{$\mathbf{p}$} & \multicolumn{2}{|c|}{ Control } & \multirow{2}{*}{$P$} \\
\hline & Pre & Post & & Pre & Post & \\
\hline \multicolumn{7}{|l|}{ Monofilament } \\
\hline Negative & $0 \%$ & $87.2 \%$ & $0.00^{*}$ & $0 \%$ & $4.3 \%$ & 0.50 \\
\hline Positive & $100 \%$ & $12.8 \%$ & & $100 \%$ & $95.7 \%$ & \\
\hline \multicolumn{7}{|l|}{ Vascular Status } \\
\hline $\mathrm{HbA1c}$ & $9.32 \pm 2.93$ & $5.98 \pm 0.86$ & $0.00^{* *}$ & $8.2 \pm 2.2$ & $8.7 \pm 2.2$ & 0.00 \\
\hline $\mathrm{ABI}$ & $0.85 \pm 0.07$ & $0.94 \pm 0.18$ & $0.00^{* *}$ & $0.8 \pm 0.6$ & $0.9 \pm 0.2$ & 0.00 \\
\hline $\begin{array}{l}\text { Pulse frequency of the dorsalis } \\
\text { pedis artery }\end{array}$ & $58.51 \pm 2.24$ & $65.95 \pm 3.42$ & $0.00^{* *}$ & $58.5 \pm 2.2$ & $59.8 \pm 2.4$ & 0.17 \\
\hline
\end{tabular}

${ }^{*}$ Monofilament measurement was tested using the McNemar test; **The measurement of HbA1c. ABI. and the frequency of the dorsalis pedis artery pulse was tested using the Wilcoxon test. 
Table 3. The summary of the mean difference test after the intervention in the control group and the intervention group

\begin{tabular}{lccc} 
Variables & \multicolumn{2}{c}{ Groups } & \multirow{2}{*}{ p-value* } \\
\hline Monofilament & Intervention (n=47) & Control (n=47) & \\
$\quad$ Negative & $87.2 \%$ & $4.3 \%$ & 0.00 \\
$\quad$ Positive & $12.8 \%$ & $95.7 \%$ & \\
Vascular Status & & & \\
HbA1c & $5.98 \pm 0.86$ & $8.7 \pm 2.2$ & 0.00 \\
ABI & $0.9 \pm 0.1$ & $0.9 \pm 0.2$ & 0.26 \\
Pulse frequency of the dorsalis pedis artery & $65.9 \pm 3.4$ & $59.8 \pm 2.4$ & 0.00 \\
\hline
\end{tabular}

*Variables of monofilament, HbA1c, ABI, and the frequency of the dorsalis pedis artery pulse were tested using the Mann Whitney test.

result indicates that proper foot exercises and care can improve the health status of diabetic patients.

Peripheral neuropathy is a common consequence of type 1 and type 2 diabetes mellitus and chronic hyperglycemia involving the vascular pathway and metabolic disorders. There are three main ways in which diabetes mellitus is considered to damage the peripheral nerves. First, neural tissues do not require insulin to transport glucose but they use an alternative metabolic polyol pathway for glucose metabolism. Glucose is converted to sorbitol, and in turn, sorbitol is very slowly converted to fructose. The accumulation of glucose from chronic hyperglycemia combined with very slow conversion rates from sorbitol to fructose results in an accumulation of sorbitol in the peripheral nerves. The increase in sorbitol causes an interference with the ion pump by producing osmotic pressure in the fluid. This reduces the nitric oxide and causes an increase in the molecular reactive oxygen and increased oxidative stress. This substance damages the Schwann cells and this causes a disruption of nerve conduction. Second, protein kinase $\mathrm{C}$ is not appropriately activated as a result of hyperglycemia, which may contribute to neurological complications.

Protein kinase $\mathrm{C}$ is an intracellular signaling molecule that regulates many vascular functions; this rate increases in diabetes. The activation of this protein in the nerve vessels can cause vascular damage and reduce nerve conduction. Third, the end products of advanced glycosylation (AGEs) are the result of the attachment of glucose metabolites to proteins. Although it is a normal component of protein, the basement membranes of smaller blood vessels and the uncontrolled blood glucose levels support the over-production of AGEs. Increased AGEs cause a thickening of the basement membrane, contributing to a reduced oxygen supply. Neuronal dysfunction is closely related to vascular abnormalities and nerve damage due to AGEs. Other damage at the microvascular level includes protein trapping (including LDL), nitric oxide inactivation, and a loss of vasodilation due to sorbitol buildup and the polyol pathways, the activation of protein kinase $C$, and an excess accumulation of AGEs. All of these factors contribute to nerve damage through myelin degeneration, causing the nerves to lose their ability to transmit signals. Peripheral neuropathy occurs when the nerves experience damage, resulting in a decrease or absence of nerve transmission with a number of possible symptoms including numbness, pain, or tingling (Harlow, Deceased, \& Herman, 2012).

The presence of peripheral neuropathy will cause a loss or a decrease in pain sensation in the foot so then it will experience trauma which results in the occurrence of ulcers. The clinical manifestations of diabetic neuropathy depend on the type of nerve fibers that experience lesions. As the nerve fibers affected by lesions can be small or large, in proximal or distal, focal or diffuse, motoric or sensory or autonomous, the clinical manifestations will be varied, including tingling, numbness, and burning sensation such as being torn (Wahyuni \& Arisfa, 2016). For this reason, it is necessary to have a tool that can detect the status of neuropathy in patients with diabetes mellitus.

A tool which can be used to detect diabetic neuropathy is $10 \mathrm{~g}$ monofilament. Monofilament is commonly used to assess the loss of protection sensation and it is recommended by several practical guidelines for detecting peripheral neuropathy in the legs (Mogre, Abanga, Tzelepis, Johnson, \& Paul, 2017). This tool serves to examine the mercel and Meissner receptors to detect their sensory function and their relationship with large diameter nerve fibers (Perkins, 2001). The early detection of sensory neuropathy can reduce the incidence rate of foot ulcers. This monofilament test can be used easily to identify sensory neuropathy (Aalaa et al., 2012). Baraz et al (2012) conducted a quasi-experimental study on 150 patients with diabetes mellitus. All patients were tested using the Semmes-Weinstein 10 g monofilament to detect their sensory neuropathy. The results showed that the sensitivity of the monofilament was $38.5 \%-61.5 \%$ at $1-8$ location points, while the specificity was $77.5 \%-95.5 \%$.

The measurement tools mentioned in this study are recommended for use to detect diabetic neuropathy, which should be performed by the health workers to minimize the further impact occurring due to the negligence of the patients in performing health care. The role of nurses is to prevent the occurrence of diabetes mellitus by conducting health education along with preventive efforts against the risk of foot ulcers. Thus, patient screening is highly recommended for detecting neuropathy immediately 
after being diagnosed with diabetes mellitus to prevent the risk of foot ulcers (Jyotsna, Kishore, \& Upadhyay, 2015)

In this study, the assessment of vascular status was performed using three measuring variables, i.e., HbA1c, brachial index or ABI and pulse frequency. The researchers collaborated with laboratory assistants to carry out blood sampling. The laboratory assistants took blood samples for the HbA1c test. Regarding the vascular status, in the beginning of the study, 94 respondents in the two groups showed poor HbA1c values $(\mathrm{HbA} 1 \mathrm{c}>6.5)$. In the intervention group, only eight patients were indicated to have HbA1c values below 6.5. The mean value of the anklebrachial index and pulse rate did not show a significant difference and it was still within the normal threshold in both groups. After the intervention and evaluation was conducted for three months, there was a significant change in the intervention group. It was shown that the HbA1c level improved but there were still 14 respondents with HbA1c values above 6.5. This showed that there were significant changes in the vascular status of the patients after regularly performing the recommended intervention.

Based on the theory, an ischemic state is a condition due to a lack of blood in the tissue that causes the tissue to have a minimum supply of oxygen. This condition happens due to a macroangiopathic process in blood vessels that leads to decreased circulation as indicated by the loss of pulse in the dorsalis pedis artery, tibialis and poplitea, atrophic and cold feet and thickened nails. The process of angiopathy in people with diabetes mellitus includes the narrowing and blockage of peripheral arteries in the lower limbs, especially the legs, due to the reduced perfusion of the distal tissue from the legs and thus diabetic foot ulcers occur (Mahfud, 2012).

The level of blood sugar in patients with uncontrolled diabetes mellitus will cause a thickening of the intima (hyperplasia of the basal artery) in the large blood vessels and capillaries. It can also cause a leakage of albumin out of the capillaries, and thereby disrupt the blood distribution to the tissues. As a result, tissue necrosis may occur, resulting in diabetic ulcers. Erythrocytes in people with uncontrolled diabetes mellitus can increase the HbA1C which causes deformability of the erythrocytes and the disrupted release of oxygen in the tissues, resulting in blockages that interfere with tissue circulation and a lack of oxygen. Such a condition may cause the death of the tissue which subsequently causes the development of diabetic foot ulcers. Increased levels of fibrinogen and increased platelet reactivity will cause a high aggregation of red blood cells so then the blood circulation becomes slow. This condition facilitates the formation of platelets in the walls of the blood vessels which will interfere with blood circulation. People with diabetes mellitus usually have a high level of cholesterol, LDL, and plasma triglyceride. Poor circulation to most tissues will cause hypoxia and tissue injury, stimulating an inflammatory reaction which stimulates atherosclerosis. Changes or inflammation in the walls of blood vessels will cause an accumulation of fat in the blood vessel lumen and a low concentration of HDL (high-density lipoprotein) as a plaque cleanser. The presence of another risk factor, which is hypertension, will increase susceptibility to atherosclerosis. Atherosclerosis may lead to decreased circulation so then the feet become atrophic, cold and the nails thicken. Another subsequent abnormality is tissue necrosis, which results in ulcers that usually starts on the lower legs (Mahfud, 2012); (Studi et al., 2012)

Vascular disease can interfere with the biomechanics in the foot which causes the risk of diabetic ulcers. This is in line with Norwood (2011), who stated that one of the risk factors which can lead to diabetes mellitus foot ulcers is peripheral vascular disease. For this reason, the routine examination of the vascular status of patients with diabetes mellitus is needed. A study conducted by Sihombing (2008) showed that the ABI and HbA1c values affected the risk of developing diabetic foot ulcers. In addition, a study by Liu et al (2010) reported that $63 \%$ of 1,524 subjects with type 2 diabetes mellitus had complications related to glycemic control levels with HbA1c $>7.5$ and where the mean of the HbA1c levels were $9.63 \%$, resulting in foot ulcers (Wahyuni \& Arisfa, 2016).

Assessing the vascular status of patients with diabetes mellitus is important as it is one of the risk factors for diabetic ulcers. Patients with poor vascular status will experience a worsening circulation especially in the peripheral area. Furthermore, old age factors and illness (cardiovascular) also worsen the condition of the arteries. If such a condition continues to be untreated, then it will increase the risk of foot ulcers. For this reason, it is necessary to take preventative measures in the form of foot care and foot exercises. Such treatments can prevent the emergence of injury as there is the protection of the barrier system (skin) and an increased strength of the foot muscles, which improves foot mobility and blood circulation in the legs.

Foot care and foot exercises are effective at improving vascular status in patients with diabetes mellitus. In this study, the effectiveness is evidenced by the decreased number of patients with diabetic neuropathy status and increased vascular status (frequency of the dorsalis pedis artery and the HbA1c and ABI values). A study conducted by Saurabh et al. (2014) found that 5-6 minutes of time devoted to providing foot care to individuals created healthy habits which could prevent disability and reduced medical expenses in the long term. Furthermore, a training program involving more than 3,000 primary care doctors in India showed that diabetic foot care was found to be very educational and this became a priority for diabetes control strategies (Saurabh et al., 2014). 
The results of this study support a research hypothesis which states that there is an effect of foot care and foot exercise on the efforts to prevent the risk of foot ulcers in patients with diabetes mellitus. The results of this study also confirm the theory that $85 \%$ of amputations of diabetic feet can be prevented by proper care and education. This study proved that performing foot care and foot exercises could prevent the risk of foot ulcers by $50-70 \%$. According to Perkeni (2015), the management of diabetes mellitus begins with applying healthy lifestyles and pharmacological interventions. The knowledge of independent monitoring, the signs and symptoms of hypoglycemia and its treatment should be given to patients. The education used to promote healthy living needs to be implemented as a part of preventive efforts. It is a very important part of holistic management of diabetes mellitus; one of which is foot care (Chiwanga \& Njelekela, 2015). Black and Hawks (2009) explained that the proper handling of foot care and the initial treatment can prevent the risk of foot infection. Effective foot care prevents the risk of ulcers turning into amputations. This is supported by Chiwanga and Njelekela (2015), who stated that practicing proper foot care reduced the risk of developing diabetic foot ulcers. Knowledge of foot care is important for health care providers in order to increase the public knowledge about the benefits of foot care (Chiwanga \& Njelekela, 2015). This is congruent with a study conducted by Netten et al. (2016) which reported that proper foot care and adherence to foot care could reduce the impact of ulcerations on the feet by $3.1 \%$ in the intervention group compared to the control group which experienced increased ulceration in the feet by $31.6 \%$ (Group, 2015). Another study conducted by Kotru et al. (2015) on foot care showed that $18 \%$ of patients in the intervention group receiving foot care developed a new ulceration. In contrast, in the control group, $31 \%$ of patients developed new ulcerations on the legs (Kotru et al., 2015). Another study by Chiwanga and Njelekela (2015) also revealed that out of the 404 respondents involved in the study, 15\% had foot ulcers, $44 \%$ had neuropathy and $15 \%$ had a history of peripheral vascular disease. The rate of peripheral neuropathy affects the emergence of foot ulcers. About $48 \%$ of respondents receiving foot care education could perform foot care independently at home and adhered to the recommended advice. Meanwhile, $27 \%$ of the respondents checked their feet at the doctors at least once after being diagnosed(Chiwanga \& Njelekela, 2015).

In addition to foot care, physical exercises can be used as part of the treatment of diabetes mellitus. Performing exercises (including weight-bearing activities) is recommended as it can improve glycemic control. The exercises should be measurable, organized, controlled, and continuously practiced. The recommended intensity is $40-70 \%$ of mild to moderate activity (Studi et al., 2012).

Diabetes causes weakness in the legs. It also changes the function of the legs and therefore it is necessary to emphasize the importance of exercising the lower limbs (Kivlan, Martin, \& Wukich, 2011). However, there has been no evidence of studies that have adapted specific foot training as recommended in this study; only indications for regular exercises were found (18). Nonetheless, regular exercise which is supervised by professionals is very important for the improvement of muscle strength, mobility, peripheral pulses, and risk assessment. Increased muscle strength is not expected to occur since there is no use of burden when the exercise is performed. Ankle biomass in diabetic clients is detached from neuropathy as there is decreased mobility, increased plantar pressure and changes in foot kinematics (18). These changes can affect the patients when it comes to increasing pressure on the fifth toe and medial area of the heel, which is associated with the risk of plantar ulceration (Gurney, Marshall, Rosenbaum, \& Kersting, 2013).

The results of the study conducted by Iunes et al. (2014) showed that the guidelines of self-care could change the leg alignment and reduce the amplitude of lateral oscillation of the lower limb when home exercises are performed. However, it was found that foot evaluation and self-care guidelines were not frequently carried out by the health workers even though the practice of preventing diabetic foot complication has been found to be very important (Iunes et al., 2014). Performing exercises is the first line action in the treatment of diabetes. Exercises can reduce blood glucose levels by taking the glucose to the active muscles. Exercises also stimulate the translocation of glucose transporter type 4 (GLUT4), increase glucose uptake into the muscle cells and compensate for the insulin sensitivity disorders associated with diabetes (26). Although exercises and detainees provide benefits for diabetic patients, the combination of both is more effective at controlling blood glucose. Exercises also increase insulin action from 2 up to 72 hours(Shrivastava, Shrivastava, \& Ramasamy, 2013).

In addition to a short-term improvement in glucose control and insulin action, long-term exercise reduces low-density lipoprotein cholesterol and systolic blood pressure in diabetic patients. It also corrects the symptoms of depression and improves quality of life related to health. Given its influence on blood glucose regulation and the role of glycemic control in preventing diabetic neuropathy, exercises should be considered as a treatment for diabetes complications (Fox, 2014). One of the recommended exercises for patients with diabetes mellitus is foot exercises (Akhtyo, 2009). Foot exercises are one of the therapies which can be provided by the nurses with the aim of launching the disrupted blood circulation as they help to strengthen the leg muscles. This is consistent with the study conducted by Wibisono (2009) as cited in Priyanto (2012) which stated that diabetic foot exercises aimed to improve blood circulation to create a smooth transport of nutrients to the tissues, to strengthen the small, calf and thigh muscles, and to overcome the limitations of 
joint motion experienced by people with diabetes mellitus. In addition, foot exercises also increase endoneurial blood flow, nitric oxide synthesis and $\mathrm{Na}$ $+/ \mathrm{K}+$-ATPase activity with the given training (Gulve, 2008).

Priyanto (2012) reported that the blood sugar levels and foot sensitivity improved in the elderly who performed the foot exercises. Wahyuni and Arisfa (2015) also found that diabetic foot exercises were effective at increasing the brachial-ankle index in patients with type 2 diabetes mellitus (Priyanto., 2012). Another study conducted by Diliberto et al (2016) also reported that performing leg exercises improved plantar foot pressure and foot biomechanics, in addition to changes in leg strength, and muscle strength(Studi et al., 2012).

In this study, it was proven that regular and continuous foot care and exercises increased the vascular status of patients by $70-80 \%$; this was reflected in the decreasing frequency of neuropathy by $70 \%$ and the increasing vascular status by $50 \%$ that using the HbA1c test and the frequency of the pulse in the dorsalis pedis artery.

In this study, a variable which showed no different in the results in the intervention group and the control group was the ankle bracelets index. This is because, at the beginning of the examination, the mean values of the brachial index ankle in the two groups before the intervention were no different. Thus, the results after the intervention were also not significantly different. However, in the intervention group, there was a significant relationship between the values of the pre- and post-intervention as there was an increase of $\mathrm{ABI}$ in the normal range of 0.9 to 1.2 .

\section{CONCLUSION}

This study concluded that foot care and foot exercises effectively increased the patient's vascular status by $70-80 \%$ in patients with diabetes mellitus. Foot exercise and foot care can be one of the independent nursing interventions used to prevent the complications of diabetes mellitus. Further research can consider the findings in this study and involve more types of laboratory tests such as cholesterol, HDL, LDL and triglyceride tests. These affect the peripheral circulatory status of the patients.

\section{REFERENCES}

Aalaa, M., Malazy, O. T., Sanjari, M., Peimani, M., \& Mohajeri-Tehrani, M. (2012). Nurses' role in diabetic foot prevention and care; a review. Journal of Diabetes and Metabolic Disorders, 11(1), 1-6. https://doi.org/10.1186/2251-6581-11-24

Chiwanga, F. S., \& Njelekela, M. A. (2015). Diabetic foot: prevalence, knowledge, and foot self-care practices among diabetic patients in Dar es Salaam, Tanzania - a cross-sectional study. Journal of Foot and Ankle Research, 8(1), 20. https://doi.org/10.1186/s13047-015-0080-y
Fox, M. (2014). Should patients with active foot ulcers be non-weight bearing or take exercise to improve cardiovascular fitness?, 17(3).

Fujiwara, Y., Kishida, K., Terao, M., Takahara, M., Matsuhisa, M., Funahashi, T., ... Shimizu, Y. (2011). Beneficial effects of foot care nursing for people with diabetes mellitus: An uncontrolled before and after intervention study. Journal of Advanced Nursing, 67(9), 1952-1962. https://doi.org/10.1111/j.13652648.2011.05640.x

Group, I. W. (2015). IWGDF Guidance on the diagnosis , prognosis and management of peripheral artery disease in patients with foot ulcers in diabetes on the Diabetic Foot IWGDF Guidance on the diagnosis, prognosis and management of peripheral artery disease in patients with .

Gulve, E. A. (2008). Diabetes : Benefits, Challenges, and Adjustments to Pharmacotherapy, 88(11).

Gurney, J. K., Marshall, P. W. M., Rosenbaum, D., \& Kersting, U. G. (2013). Test-retest reliability of dynamic plantar loading and foot geometry measures in diabetics with peripheral neuropathy. Gait and Posture, 37(1), 135-137. https://doi.org/10.1016/j.gaitpost.2012.06.007

Harlow, S. D., Deceased, M. R. S., \& Herman, W. H. (2012). Prevalence, Risk Factors, and Sequelae of Peripheral Neuropathy in a Population-Based Cohort of Mid Life Women by Kelly Renee Ylitalo A dissertation submitted iri partial fulfillment of the requirements for the degree of Doctor of Philosophy (Epidemiol.

Iunes, D. H., Rocha, C. B. J., Borges, N. C. S., Marcon, C. O., Pereira, V. M., \& Carvalho, L. C. (2014). Self-care associated with home exercises in patients with type 2 diabetes mellitus. PLOS ONE, 9(12), 1-14. https://doi.org/10.1371/journal.pone.0114151

Jyotsna, V., Kishore, S., \& Upadhyay, A. (2015). Categories of foot at risk in patients of diabetes at a tertiary care center: Insights into need for foot care. Indian Journal of Endocrinology and Metabolism, 19(3), 405. https://doi.org/10.4103/2230-8210.152789

Kivlan, B. R., Martin, R. L., \& Wukich, D. K. (2011). Responsiveness of the foot and ankle ability measure (FAAM) in individuals with diabetes. The Foot, 21(2), 84-87. https://doi.org/10.1016/j.foot.2011.04.004

Kotru, S., Kotru, B., \& Joshi, K. (2015). Diabetes \& Metabolism Intervention of Diabetes Foot Care Practices on the Prevention of New Diabetic Foot Ulcers in Patients with Type 2 Diabetes Mellitus, 6(2). https://doi.org/10.4172/21556156.1000494

Mahfud, M. U. (2012). Hubungan Perawatan Kaki Pasien Diabetes Melitus Tipe 2 Dengan Kejadian Ulkus Diabetik Di RSUD Dr. Moewardi.

Mogre, V., Abanga, Z. O., Tzelepis, F., Johnson, N. A., \& Paul, C. (2017). Adherence to and factors associated with self-care behaviours in type 2 diabetes patients in Ghana. BMC Endocrine 
Disorders, $\quad 17(1), \quad 20$ https://doi.org/10.1186/s12902-017-0169-3

Ramadhan, N., \& Marissa, N. (2015). Karakteristik Penderita Diabetes Melitus Tipe 2 Berdasarkan Kadar HBA1C di Puskesmas Jayabaru Kota Banda Aceh. Sel, 2(Diabetes Melitus), 49-56.

Saurabh, S., Sarkar, S., Selvaraj, K., Kar, S., Kumar, Sg., \& Roy, G. (2014). Effectiveness of foot care education among people with type 2 diabetes in rural Puducherry, India. Indian Journal of Endocrinology and Metabolism, 18(1), 106. https://doi.org/10.4103/2230-8210.126587
Shrivastava, S. R., Shrivastava, P. S., \& Ramasamy, J. (2013). Role of self-care in management of diabetes mellitus, 12(1), https://doi.org/10.1186/2251-6581-12-14

Studi, P., Ilmu, M., Keperawatan, F. I., \& Indonesia, U. (2012). Pengaruh senam..., Sigit Priyanto, FIK UI, 2012.

Wahyuni, A., \& Arisfa, N. (2016). Senam Kaki Diabetik Efektif Meningkatkan Ankle Brachial Index Pasien Diabetes Melitus Tipe 2. IPTEK Terapan, 9(2). 